$\Phi=\Phi$

\title{
Development for a quality improvement training programme for health professionals in the ministry of health and social services in Namibia
}

\author{
Julia Paul Nangombe ${ }^{1 *}$, Amukugo Hans Justus ${ }^{2}$ \\ ${ }^{1}$ Quality Assurances and Quality Improvement. Office of Vice President, Veterans Affairs, Republic of Namibia \\ ${ }^{2}$ Lecturers, School of Nursing and School of Public health, Faculty of health Sciences University of Namibia \\ *Corresponding author E-mail: julianangombe@yahoo.com
}

\begin{abstract}
The paper describes the steps followed in the development of a quality improvement training programme for health professionals. This was echoed by the facts that the health professionals are facing in their quest for quality health care delivery. In Namibia, most health care facilities have not been yielding good results in response to patients' health care needs. Health care dynamics are complex and inundated with several factors; among others new methods, speed of improving medical science and technology, as well as increasing demands of the clients to address emerging and re-emerging diseases.

In order to achieved that the five phases of programme development by Meyer and Van Niekerk (2008) were modified to facilitate the programme development. Quality improvement training for health professionals. Those five phases were situational analysis; conceptual framework; developing of the training programme; development of the guidelines for the implementation; and Evaluation of training programme.
\end{abstract}

Keywords: Development; Quality Improvement; Training Programme; Health Professionals

\section{Introduction}

Quality improvement (QI) training refers to any activity that explicitly aims at teaching health professionals about methods that could be applied to analyse and improve quality health care (The Health Foundation, 2012). A QI training programme would equip and empower health professionals with skills and competencies to improve health care delivery and meet the increasing demands of the patients. The need exists in health care "...to provide appropriate training and continuous medical education programs, the aptitude to learn from failure and to be pro-active in the risk assessment" (Casali, Marraro, Spada, \& Steffano, 2013). "[T]here is a responsibility on healthcare providers to deliver high quality education and training not just for their students but for all their staff in order to ensure high quality and safe patient care" (Department of Health, 2013).

Health care systems are becoming more complex with paradoxical challenges resulting into inefficiencies due to ever increasing science and knowledge in medicine, which makes it difficult to internalise and understand, as well as to implement certain procedures (Casali et al., 2013). On the other hand, health professionals seem to be blamed and humiliated due to contradictions and disputes that leads to less improvement in quality health care while hampering "...innovation to improve the quality of care and health outcomes" (Towne, Solovy and Hoppszalern, 2006). Research indicates that health care systems in both developed and developing countries seem to lag behind, consistent with preventable medical errors and sluggish methods that are often blamed upon health professionals (health providers). Research indicates persistent variations in the degree of providing care resulting in unpleasant results, inefficiencies, constant mistakes, unacceptable services, and poor health care outcomes. Aasland and Forde (2005) attest that at times the consequences of mistakes and errors during treatment and care are borne by the health professionals who suffer the blame and humiliation from their patients and family members. While "the full responsibility for quality lay beyond individual physicians' immediate reach, requiring organizational action" (Towne et al., 2006). "[W]e need to turn our cultural approach to recognize that bright, well-educated, skilled and well-intentioned professional will make errors" (Casali, et al., 2013). Unless they are continually equipped and capacitated with the appropriate knowledge, skills, and aptitudes to perform their duties effectively and efficiently.

Although quality health care has been part of national policy frameworks and standards that guide the provision of health care and services, at the time of this study health care facilities were not yet accredited to measure and benchmark the provision of quality health care delivery and sustainable improvement, as well as operate under prescribed quality standardised measures at health care facilities. The findings of this study indicated that not even one facility could meet the criteria for accreditation, which was assessed by the Council for Health Service Accreditation of Southern Africa (COHSASA) in 2013. In comparison, most hospitals in Europe are accredited and operated according to the International Organisation for Standardisation (ISO) that has specifically developed several indicators and guidelines that are used at those hospitals to design quality management systems, quality assessment, and accreditation.

$\emptyset$ vretveit* (2003) outlines several strategies that measure the processes, patient satisfaction, team building, capacity development, and health care outcome, among others "...quality management 
system, Total quality management (TQM), quality assessment and accreditation". TQM uses a systematic and consistent approach to keep improving and satisfying the needs of the clients. It is one of the best "...[s]tructured organisational process [es] for involving personnel in planning and executing continuous flow of improvement to provide quality health care" (McLaughlin \& Kaluzny, 2006). Although TQM and QI principles seem widely accepted, their implementation is still modest at Namibian health care facilities while these principles mostly remain concentrated in developed countries. This could be one of the difficulties to completely understand and apply the methods in different health care contexts. Given diverse challenges faced by the health care facilities and technical aspects involved to adopt the methods, the implementation of a QI training programme may require a lot of commitment and support. Firstly, rigorous collection and interpretation of information to generate reports might be slow, especially in the rural areas where public health care facilities may not have adequate equipment and enough skilled personnel. Secondly, health professionals might view a high level of involvement and commitment as an additional burden on their workload. Thirdly, quality needs to be part of the daily actions and behaviour of both health care providers and patients. It requires a particular mind set to understand the roles of improving health care services. For QI to be successful at health care facilities, several factors need to be enhanced; such as understanding policies and standards, adequate resources, infrastructure, research and information to generate evidence for quality planning, and decision making.

Research indicates that TQM and continual quality improvement (CQI) principles can be applied to strengthen a health system to improve its quality. This could be particularly useful in Namibia where people demand basic services and the health service users raise their issues with the Ministry of Health and Social Services (MoHSS). It becomes essential to ascertain the extent to which health care facilities have responded to this call. Against this background, it is important to analyse the responses to QI and QA and how it could be used to develop a framework for quality health care delivery at the health care facilities in Namibia.

The main focus of this study was to develop a training programme to empower and equip health professionals with the righ knowledge, skills, aptitudes, and behaviour to apply the methods and techniques with the purpose of improving quality health care delivery.

\section{Problem stament}

Quality improvement training programme might not be new in health care system however, there seems to be scanty or inadequate training to empower health professionals to understand the principles and methods to meet the expectations of the patients and families within the health facilities in MoHSS. This study took cognisance of QA and QI standards and processes in the health care, and in general health care systems of both developing and developed countries in the midst of serious quality problems owing to the inability to respond to health care needs and patient safety. For example, recent developments in Ghana, America, Britain (National Health Service, 2006).

Namibia emphasise the need for quality improvement in health facilities with the purpose of reducing errors in medical care while facilitating quality health care delivery. This sentiment is supported by the Agency for Healthcare Research and Quality (AHRQ) (2002) that research has even documented several quality problems of variations and disparities in services; such as underuse, overuse, and misuse of services.

These problems might be especially hastened by increasing health care demands and knowledge obsolescence, which require learning new methods to improve quality health care services. "Multiple innovations in therapy and technology, [a] fast increase in sciences and medicines, new substances [sic] procedures, electronic devices or robotics has [sic] increased diagnostic capabilities and other range [sic] of possible interventions" Sottas, Höppner, Kickbusch, Pelikan and Probst (2013).

These developments prompt the need for an educational training programme to update the knowledge, skills, aptitudes to respond to health care demands. In Namibia, a quality improvement training programme seems to be the best option to address quality health care issues; more especially when the MoHSS has planned a new direction in quality improvement and quality assurance to promote quality health care delivery. However, these endeavours are moderately or inconsistently pursued to empower health professionals at the health care facilities. According to the National Leadership and Innovation Agency for Health (NLIAH) (2008), most health systems face challenges in providing high quality patient care to meet health care needs. A study by the Partners for Health Reformplus (2005) concurs that “... [c]linical practice does not meet national standards; there is low satisfaction of both employees and patients, as well as inefficient use of resources".

Research has even emphasised that health professionals need to be constantly involved in acquiring knowledge, skills, and aptitudes that would enable them to apply new methods to providing quality health care that meets the health needs of their patients (Agency for Research and Quality (AHRQ), 2005). Although health care facilities strive to achieve quality, there seems to be inadequate quality improvement programmes that could guide and prepare health professionals in their quest to provide quality health care delivery.

Furthermore, over the past years, there have been growing frustrations and a priority to focus on QI and QA approaches in the MoHSS with the result that little improvement would be achieved without a proper understanding of the conceptual framework at all operational levels (MoHSS, 2014). Unless health professionals understand the principles of quality improvement and quality assurance, health care services will remain compromised. Several complaints about mistakes and errors appear in daily print and electronic media and serve as an indication of poor results and an inability to meet patients' health needs.

It seems there are unexplored perspectives that are needed to understand the conceptual framework and the application of quality improvement methods towards safe, effective, efficient, and timely health care services. Hence, there is a need to develop a quality improvement educational programme to facilitate quality health care delivery at the health care facilities.

\section{Aim of the study}

The aim of this study was to develop a training programme for health professionals that facilitate quality health care and services delivery at the health care facilities.

\section{Objectives of the study}

The study objectives were to:

- analyse the present situation of quality health care / service delivery at health care facilities;

- explore and describe experiences of top manager and health professionals with regard to quality health care / service delivery at health care facilities;

- describe a conceptual framework for the development of a training programme for health professionals to facilitate quality health care / service delivery at health care facilities;

- develop a programme for health professionals to facilitate quality health care / service delivery at health care facilities;

- describe guidelines for the implementation and evaluation of quality health care / service delivery by the health professionals at health care facilities; and

- Describe guidelines for evaluation of the programme to facilitate quality services delivery by health professionals at health care facilities. 


\section{Methodology}

Five phases as modified adopted from Meyer and Van Niekerk (2008) such as situational analysis; conceptual framework; developing of the training programme; development of the guidelines for the implementation; and evaluation of training programme are described as follow:

Phase 1: The first phase comprised a situation analysis to gather information based on two objectives. The findings formed for the foundation for developing the educational programme.

The first objective of the situation analysis focused on the health facilities to understand the status of existing quality improvement and quality assurance processes. The top management members completed a self-administered checklist to confirm the approaches in relation to quality health care delivery at the health facilities. The checklist was constructed inline with 5S-Kaizen-TQM approach of Deming's theory.

Part two of the situation analysis sought to explore and describe the experiences of top managers and health professionals about quality improvement and quality assurance at the health facilities with the view of improving quality health care delivery. During this phase, individual interviews and FGDs with health professionals and managers were conducted.

Phase 2: The conceptual framework of this study was based on the practice orientated theory of Dickoff (1968) that assisted with explaining the concepts used in developing the quality improvement training programme for health professionals at the health facilities. Dickoff's (1968) practice orientated theory consists of the agent, recipients, context, procedure, dynamics, and the terminus. In this study, the agent was a quality specialist, the recipients were health professionals, the context was the health facilities, the dynamics were challenges that health professionals were experiencing; the procedure was the training programme, while the terminus was knowledgeable and skillful health professionals in quality health care delivery.

Phase 3: During the development of the quality improvement training programme, two main theories were adapted. The most prominent one was a model by Meyer and Van Niekerk (2008), which was adapted to guide the process of developing the training programme. Kolb's experiential learning theory was used to explain the learning process and styles of developing knowledge through experiences. The educational programme included the purpose / aim, objectives, structure / design, facilitation process, implementation process, and evaluation of the programme.

Phase 4: This phase of the study focused on developing the guidelines for implementing the training programme. The guidelines in this study were developed to direct and promote the effective implementation of the training programme. The guidelines outlined the process, activities, and elements required to implement the programme. The purpose of the guidelines was to assist the implementers and beneficiaries on steps to be followed in implementing the training the programme.

Phase 5: The last phase five focused on the evaluation of the quality improvement training programme. To achieve that, two practical frameworks were adopted in this study, namely the United Nations Population Fund (UNFPA, 2013) based on four phases that was used to guide the team of evaluators or facilitators how to conduct the evaluation.

\section{Ethical aspect and validity and reliability}

The study achieved trustworthiness by applying the criteria of dependability, transferability confirmability and credibility (Guba \& Lincoln, 1994; Babbie, 2008; Lincoln \& Guba 1986; Schwandt, Lincoln, \& Guba 2007).

\section{Findings}

\subsection{Phase one}

Objective 1 revealed some ambiguities in the availability of policies and guidelines, leadership to facilitate care delivery, health system infrastructure, patient safety, as well as research and information to facilitate quality health delivery. The following were the findings from the objective no 2 and are as follow:

- Availability of visionary leader

- Lack of supportive supervision

- Inadequate training health professional to facilitate quality health care deliver

- Availability of quality teams

- Inappropriate physical facility design against quality standards

- None-involvement of patient in

Objective 2 was accomplished with the identification of five themes and 18 sub-themes. And they are illustrated in table 1

Table 1: Themes and Sub-Themes

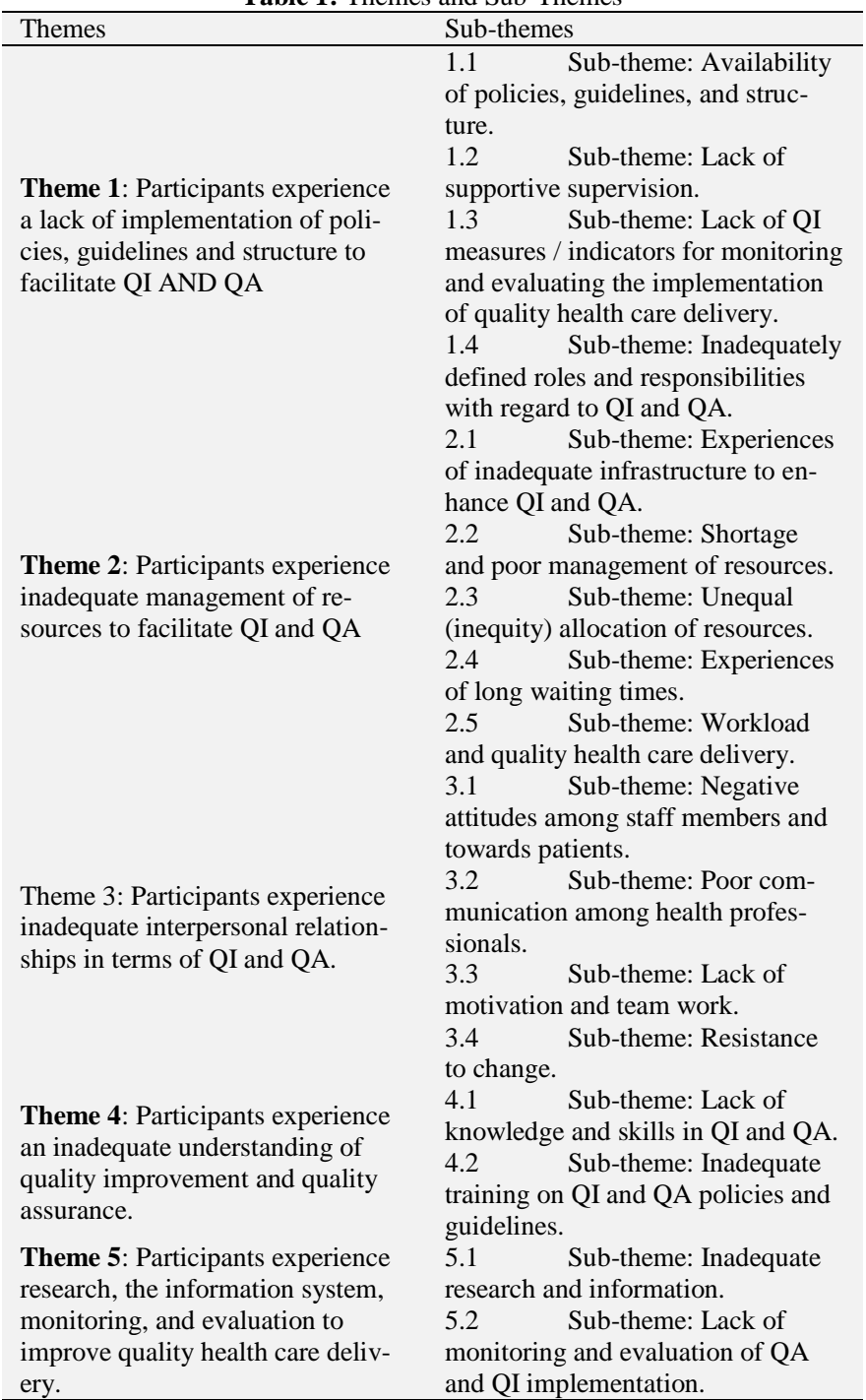

\subsection{Phase 2}

A reasoning map by Dickoff, James and Wiedenbach (1968) in Mothiba (2012) was adopted in developing an educational programme to facilitate quality health care delivery at the health care facilities.

In this study, the hierarchical representation of the reasoning map consisted of the following components: Agent (specialist), recipi- 
ents (health professionals), context (health care facilities), dynamics, procedures, and terminus (station/position). Each component consisted of elements that were part of the study findings, which assisted with developing a Quality Improvement Educational Pro- gramme for Health (QIEPH) to empower health professionals with knowledge, skills and abilities to facilitate quality health care delivery.

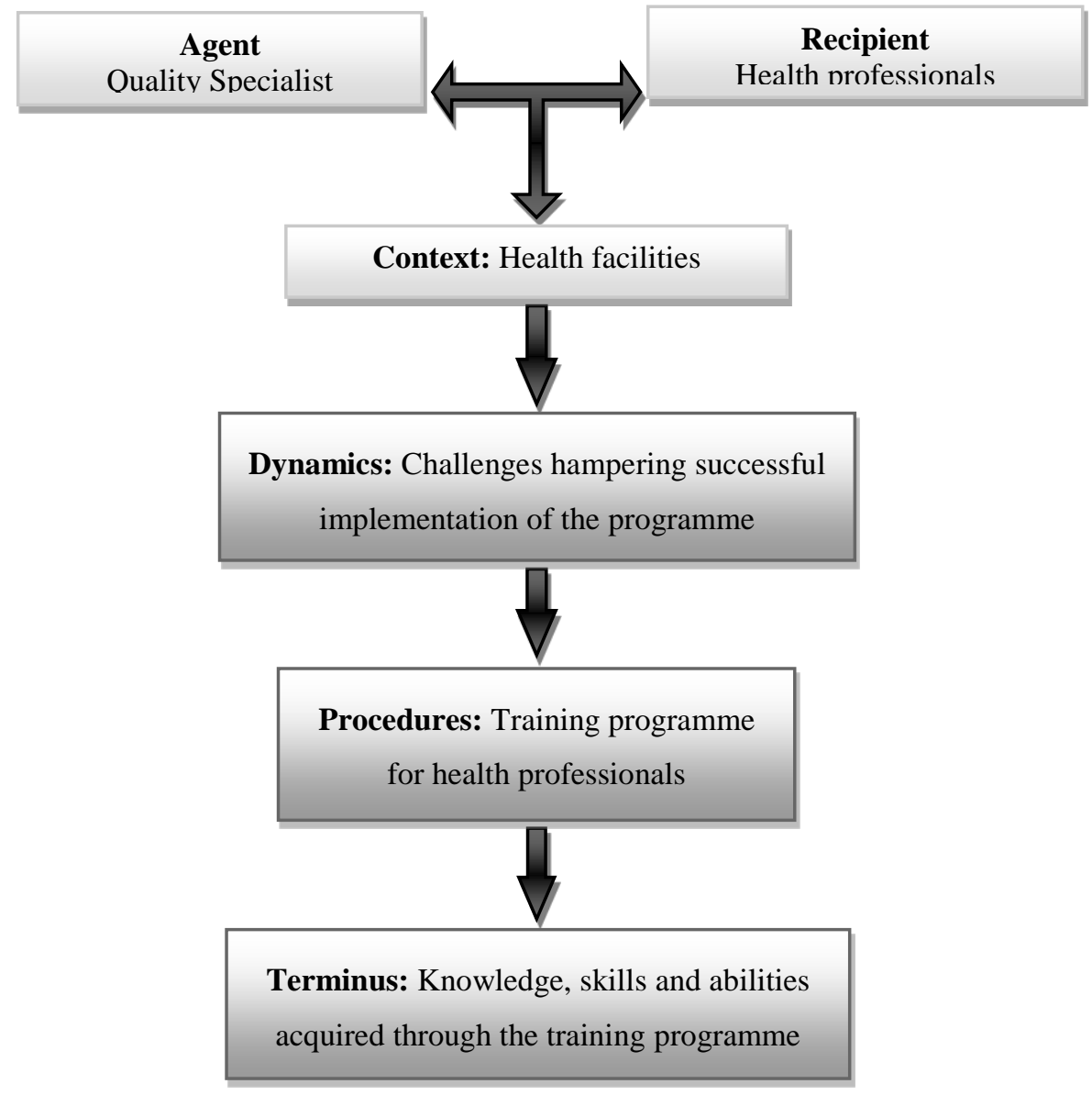

Fig. 1

\subsection{Phase 3}

Table 2: The Following Educational Programme were Developed Namely:

\section{Headings}

1. Purpose /aim of the educational programme

2. Programme objectives

3. Benefits of the programme

4. Programme structure / design

5. Programme process (facilitation process) Content of a training programme

The purpose of this training programme was to empower health professionals with appropriate KSAs to improve health care and service delivery at the health care facilities.

- $\quad$ Equip health professionals on policies and guidelines on QA and QI to facilitate quality health care

- Empower health professionals on management and utilisation of resources to enhance quality health care delivery

- Empower health professionals on mechanisms to improve interpersonal relationships among health professionals and between clients to enhance quality health care delivery.

- Empower Health professionals on application of QA standards and QI processes, methods to enhance quality health care delivery

- $\quad$ Benefits to the participants (recipients)

- Benefit to the society

- $\quad$ Profession (body of knowledge)

- Name of the programme

- Unit standards

- Quality assured component (national qualification standard)

- Outcomes standard

$-\quad$ Duration of training
- $\quad$ Completion of successful training

* Educational approaches

Kolb's experiential learning

Knowles' theory of adult learning

Problem-based learning approaches

Learning environment

Programme components / content 


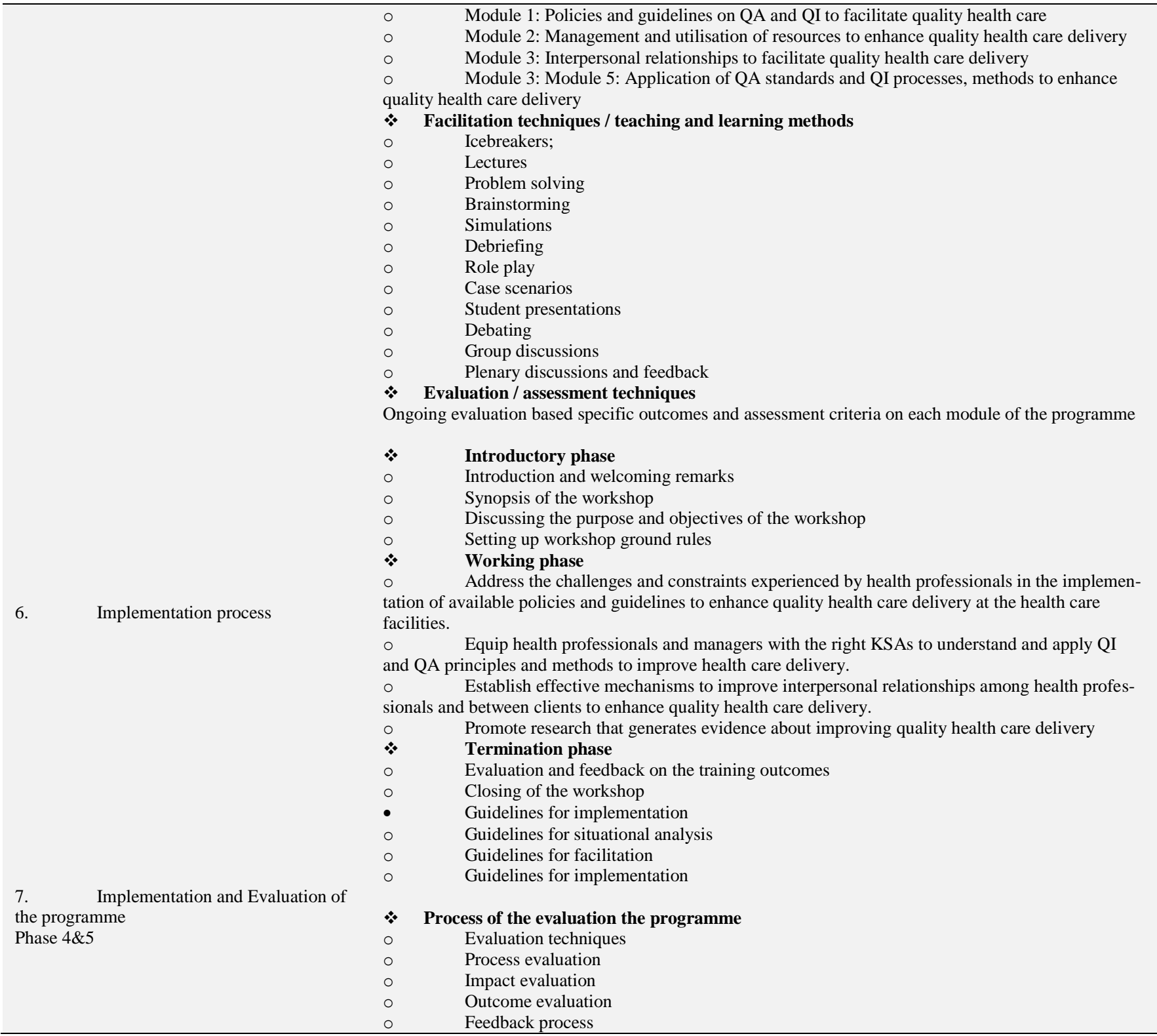

\section{Conclusion}

This study produced valuable material and documents, which captured the real challenges faced by health professionals in pursuit of providing quality health care and services to the clients (patients). The study developed a conceptual framework on which the quality improvement training programme was based. A quality improvement training programme was the primary objective of this study and main contribution to the field of quality management and improvement in health care. The study formulated the guidelines for implementation and evaluation of the training programme. The training programme contributes to the body of knowledge by seeking to facilitate the successful implementation of the training programme at the health care facilities in the MoHSS. An evaluation tool was developed to evaluate the process of the training programme with the view of determining whether the components identified as critical for successful implementation of the programme were appropriate and relevant to address the challenges and constraints that obstructed quality health care delivery at the health care facilities.

The main purpose of the study was to develop a training programme with enhanced KSAs for health professionals to address the gaps between the current state of health care and the anticipated quality of health care and service delivery. The objectives were, therefore, discussed according to the five phases of the study. The phases of the study refer to the steps followed in coherent and organised format, which assisted with presenting the data in an understandable manner to achieve the objectives.

\section{Limitation}

This study had few limitations that might have influenced the results of the study. The study focused mainly on the public health care facilities to the exclusion of the private health care facilities. Their inclusion might have identified quality practices that could have benefitted the quality improvement of actions in the public health sector. Due to financial constraints and time, the views of community members (patients / families) could not be captured, hence quality was not analyzed from the perspective of patients. Using the English language to communicate might have contributed to barriers for people to express their opinions freely. This was a cross-sectional study that was limited to six regions due to the vastness of the country and study time frame. It focused mainly on six health care facilities in six regions of Namibia. There might be some exclusion of quality aspects in other health care environments; these quality aspects could be useful for comparing similarities and differences among different settings. Any change in methods, processes, and structures might also influence data omissions. The magnitude of the study required more people to assist with data collection but due to limited funds and time, it was not possible to recruit and train research assistants. Due to time and 
costs, it was neither viable, nor possible to extend the coverage to other contexts.

\section{Recommendation}

A number of recommendations are raised based on the results of the study with an emphasis on empowering health professionals to enhance quality health care delivery at the health care facilities. In order to address the critical challenges and constraints hampering quality health care delivery, the management should establish mechanisms to streamline the policies and guidelines. Therefore, the researcher recommends that policies and guidelines should form part of the quality improvement training programme in order to understand the principles and standards that are meant to enhance quality health care delivery at the health care facilities. Health professionals, as the recipients of the training programme, are required to assume an active role to participate in the training programme. To address the array of challenges, a need exists to empower health professionals to be confident when applying quality improvement tools, as well as to understand and eliminate unnecessary causes of process variations in health care and service provision.

In terms of the practice of quality improvement, this study has generated valuable information in abundance that would contribute to the methods and approaches in the field of quality management in health care. The study has expanded the conceptual framework and theories to be applied in developing the quality improvement training programme, approaches in training and learning methods, as well as guidelines for implementing and evaluating the training programme that would be applied at the health care facilities and even institutions of high learning. In order to complete the loop of quality health care delivery and improve the health care services, an enquiry into the perceptions of patients' satisfaction should be conducted to compare the findings and generate data for adequate planning and decision-making about patient safety. There is currently a vacuum of data on this continuum, which has been a limitation of this study to understand quality health care delivery from the perspective of the patients.

\section{References}

[1] The Health Foundation (2012). Evidence scan: Quality Improvement training for healthcare professionals.

[2] Casali, M., Marraro, G., Spada, C. \& Steffano, G. (2013). Current Topics. Healthcare Safety and Accountability. (Eds.) Retrieved February 3, 2015 from http://www.healthcsa.org.

[3] Department of Health Education and Welfare (2013). The Belmont Report. Ethical Principlesand Guidelines for the Protection of $\mathrm{Hu}$ man Subjects of Research. The NationalCommission for the Protection of Human Subjects of Biomedical and BehavioralResearch.

[4] Towne, J., Solovy, A. \& Hoppszalern, S. (2006). Cover Story: Measuring Value. Most Wired Winners. Hospitals and Health Networks. Retrieved February 3, 2015 from http//:www.thehastingscenter.org/.../Health\%20Care\%20Quality\%2 OImprovem.

[5] Aasland, O. G. \& Forde, R. (2005). Impact of feeling responsible for adverse events on doctors' personal and professional lives: The importance of being open to criticism from colleagues. Qual Saf Health Care. 14(1): 13-17. PMid: 15691998. Retrieved February 3, 2015 from http://dx.doi.org/10.1136/qshc.2002.003657.

[6] Øvretveit, J. (2003). Health Planning Management. The International Journal of Health Planning and Management. Vol. 18(3), pp. 233-246, June/July 2003. DOI: $10.1002 / \mathrm{hpm} .712$. John Wiley \& Sons, Ltd. http://dx.doi.org/10.1002/hpm.712.

[7] McLaughlin, C. P. \& Kaluzny, A. D. (2006). Continuous Quality Improvement in Health Care. Theory, Implementations and Applications. (3rd ed.). Jones and Bartlett Publishers. United States of America.

[8] Agency for Healthcare Research and Quality (AHRQ) (2002). Improving Health Care Quality. U.S. Department of Health and Human Services Public Health Service. Retrieved June 12, 2014 from http://www.ahrq.gov. No. 2, September 2002.
[9] Agency for Healthcare Research and Quality (AHRQ). Chapter 4 Timeliness: National Healthcare Quality Report, 2008. March 2009. Agency for Healthcare Research and Quality, Rockville, MD. http://www.ahrq.gov/research/findings/nhqrdr/nhqr (accessed Sept. 23, 2014). Agency for Healthcare Research and Quality (AHRQ). State Snapshots from the 2005 National Healthcare Quality and Reports. March 2006. Retrieved June 16, 2015 from http://www.qualitytools.ahrq.gov/qualtiyreport/2005/state.

[10] Agency for Healthcare Research and Quality. Understanding Quality Measurement. Rockville, MD. September 2012. Retrieved September 26, 2014 from http://www.ahrq.gov/professionals/qualitypatient-safety/qualityresources/ tools/chtoolbx/understand/index.html.

[11] Sottas, B., Höppner, H., Kickbusch, I., Pelikan, J. \& Probst, J. (2013). Thinking about the future of health and care. Educating Health Professionals: An Intersectoral Policy Approach. Careum Foundation, June 2013, working paper 7. Retrieved February 3, 2015 from http://www.careum.ch.

[12] National Leadership and Innovation Agency for Health (2008). Engaging Clinicians in a Quality Agenda. Resource Paper. Retrieved July 28, 2014 from http://www.nliah.wales.nhs.uk.

[13] Meyer, S. \& Van Niekerk, S. (2008). Nurse educator in practice. Cape Town. Juta \& Co Ltd.

[14] Kolb, A. \& Kolb D. A. (2001). Experiential Learning Theory Bibliography. Boston, MA: McBer and Co. Retrieved 23, 2014 from http://trgmcber.haygroup.com/Products/learningbibliography.htm.

[15] Kolb, D. A. (1984). Experiential Learning. Englewood Cliffs, NJ: Prentice Hall.

[16] United Nations Population Fund (2013). How to Design and Conduct a Country Programme Evaluation at UNFPA. Retrieved November 24, 2014 from http://www.unfpa.org/admin-resource/howdesign-and-conduct-country-programme-evaluation-unfpa\#sthash.

[17] Guba, E. G. and Lincoln, Y. A. S. (1989). Fourth Generation Evaluation. London: SAGE Publications. 443

[18] Guba, E. G. and Lincoln, Y. A. S. (1994). Competing Paradigms in Qualitative Research. Retrieved November 21, 2014 from https://it.scribd.com/doc/37520662/Guba-Lincoln-Competing.

[19] Babbie, E. (2008). The Basic of Social Research. International Student Edition. U S A. Thomson Wadsworth

[20] Schwandt, T. A, Lincoln, Y. S. \& and Guba, E.G. (2007). Judging interpretations: But is it rigorous? 